\title{
La reforma urbana de la colonia Libertinorum Carteia en época augustea. El edificio basilical
}

\author{
Juan BLÁNQUEZ PÉREZ \\ Universidad Autónoma de Madrid \\ juan.blanquez@uam.es \\ Lourdes RoLdÁN GómEZ \\ Universidad Autónoma de Madrid ${ }^{1}$ \\ lourdes.roldan@uam.es
}

\section{RESUMEN}

En este trabajo analizamos la reforma acometida en la urbe de Carteia (San Roque, Cádiz) en época augustea y, especialmente, dentro de la misma, la construcción del denominado, hasta la fecha, "edificio aterrazado augusteo". Se trata de uno de los edificios de carácter monumental más interesantes reconocido, como tal, durante los trabajos del Proyecto Carteia (Fase II, 2006-2013) cercano al, hoy desaparecido, cortijo del Rocadillo. Gran parte de este edificio fue excavado entre los años 1960 y 1985 por diferentes equipos, pero ha sido a partir de las nuevas excavaciones (2007 y 2009) cuando se ha podido llevar a cabo un estudio completo de su estructura arquitectónica, así como de sus técnicas constructivas con el objetivo de determinar la tipología del edificio y su funcionalidad. La nueva documentación obtenida, así como su valoración en relación con los edificios y espacio inmediatos, nos permiten interpretar hoy esta construcción -sin duda de carácter monumenta- como una posible basílica construida en el momento de una programada renovación urbana de toda esta zona de urbe carteiense, en la cual se ubicaba el foro de la ciudad, en época augustea.

Palabras clave: Carteia. Colonia latina. Basílica y foro augusteos. Técnicas constructivas.

\section{The Urban Reform of the Colonia Libertinorum Carteia during the Augustan Era. The Basilica Building}

\begin{abstract}
In this paper we analyse the reform that took place in the city of Carteia (San Roque, Cadiz) during the Augustan Age and, specially, inside it, the construction of the so-called "Augustan terraced building". It is one of the most interesting monumental buildings, identified in that way during the Carteia Project works (Phase II, 2006-2013) near the "cortijo (a kind of country house) del Rocadillo", which no longer exists. Most of this building was dug between 1960 and 1985 by diferents pojects. However, it has been

1 Este trabajo se enmarca dentro de las investigaciones llevada a cabo por el $\mathrm{I}+\mathrm{D}+\mathrm{I}$ Métodos de análisis de la Arquitectura, Técnicas y Sistemas Constructivos romanos. Definición de la Cultura Arquitectónica en el Círculo del Estrecho (HAR.2012-36963-C05-01), con el preceptivo permiso concedido por la Junta de Andalucía, a través de su Consejería de Educación Cultura y Deporte y dentro, también del Grupo de Investigación de la UAM (HUM-F.076) Territorio, Arqueología y Patrimonio en el Campo de Gibraltar.
\end{abstract}


due to the new archaeological digs (in 2007 and 2009) that a new and complete study of its architectural structure and construction techniques has been performed, following the main purpose of establishing its typology and function. The new documentation and data, as well as its assessment in relation to the buildings and spaces nearby, allow us to interpret this undoubtedly monumental construction as a possible basilica, erected in a moment of planned urban renovation of this area in the city of Carteia-where the forum was placed-, in the Augustan Age.

Key Words: Carteia; Latin Colonia. Augustan basilica and forum. Construction techniques.

Sumario: 1. Introducción. 2. El edificio basilical. 2.1. La relación del edificio con la ínsula republicana. 2.2. Elementos estructurales. 2.3. La plataforma superior: pórticos y columnas. 2.4. La escalera. 2.5. El muro Norte de fachada. 2.6. Cronología. 3. Definición e interpretación del edificio.

\section{Introducción}

Las excavaciones que, desde 1994, se llevan a cabo en Carteia por un equipo de investigadores de la Universidad Autónoma de Madrid (Estudio histórico-arqueológico de la ciudad púnico-romana de Carteia, 1994-1999 y Proyecto Carteia. Fase II, 2006-2013), han permitido documentar cómo la presencia romana en esta urbe -primero como ciudad peregrina y después como colonia latina- no se reflejó de manera inmediata en su urbanismo ni en su arquitectura; todo lo contrario. Así, en la zona mejor conocida de la ciudad hasta la fecha, aquella que corresponde a la ocupada por la anterior urbe púnica y donde, con posterioridad, se ubicó el foro romano, se ha podido documentar una continuidad que, al igual que refleja la cultura material aparecida, no permiten establecer una ruptura tajante entre la urbe púnica y la republicana. ${ }^{2}$

La romanización oficial de Carteia y de su territorio comenzó con el establecimiento de la colonia en el 171 a.C., fundación ésta narrada por Tito Livio en su $A b$ urbe condita (XLIII 3.1-4). ${ }^{3}$ Sin embargo, no fue hasta finales del s. II a.C. cuando, arqueológicamente hablando, se produjeron significativos cambios en las áreas religiosa y defensiva. Fue entonces cuando tuvo lugar la construcción de un templo, de tipología itálica, con acceso desde un espacio abierto o plaza delante del mismo y que amortizó el antiguo espacio religioso en origen de época púnica (Fig. 1). De manera paralela, se llevaron a cabo otras construcciones que, apoyadas en el lienzo murario púnico, amortizaron la puerta monumental de época bárquida. ${ }^{4}$

A partir de entonces Carteia entró en un periodo de progreso económico avalado, entre otras cuestiones, por el inicio de emisiones monetales y por el despegue definitivo de su industria pesquera y conservera reflejada, incluso, en sus acuñaciones. ${ }^{5}$ Durante aquel nuevo periodo, aun a pesar de los problemáticos momentos que tuvieron que suponer las guerras civiles, dado su apoyo al bando pompeyano, así como de

\footnotetext{
2 RoldÁn ET ALII 2003; RoldÁN ET ALII 2006.

3 Presedo et alit 1982; Roldán et ali 1997.

4 Blánquez 2006a; Blánquez 2014.

5 Chaves 1979; Arévalo 2008.
} 
la necesaria redefinición de su territorio a raíz de la fundación de Iulia Traducta, de nuevo la arqueología ha testimoniado importantes reajustes urbanísticos.

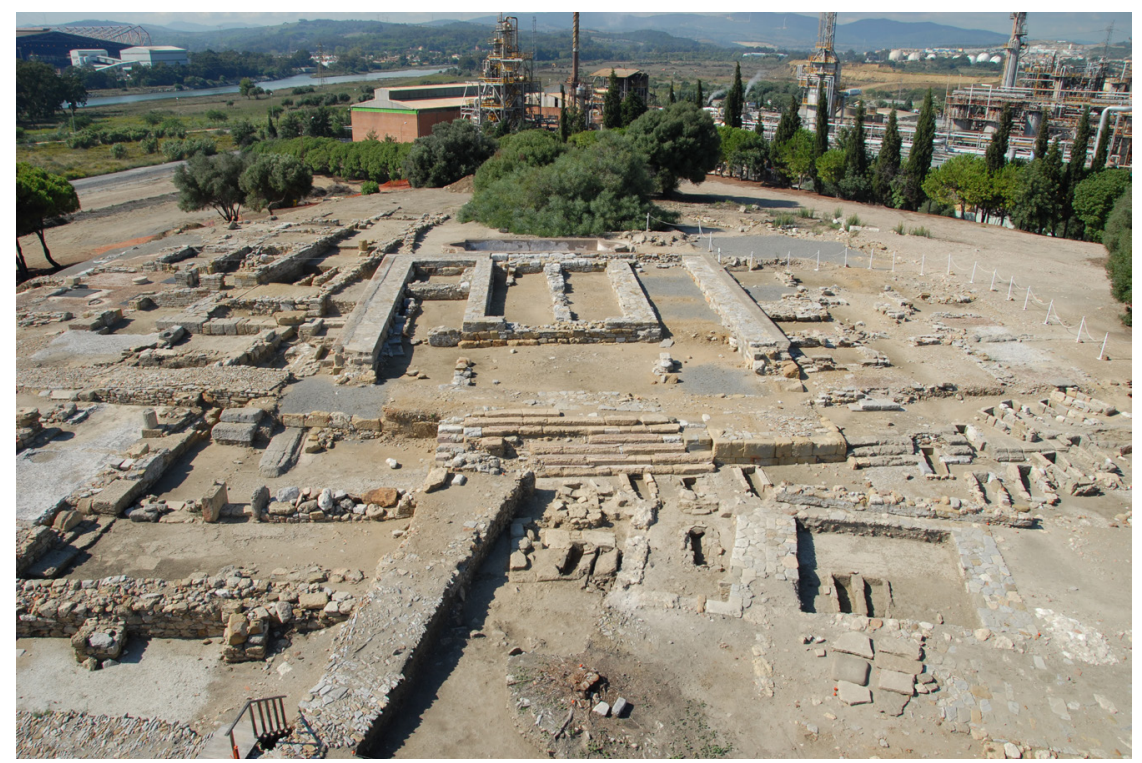

Fig. 1. Vista general del templo romano de Carteia (San Roque, Cádiz), con la posible plaza foraria delante ocupada por construcciones tardoantiguas. (C) Proyecto Carteia UAM, 2007.

Fue especialmente a partir del final de las citadas guerras civiles cuando tuvo lugar la consolidación del modelo urbano romano en Carteia. Ello lo vemos, todavía hoy, reflejado en la definitiva ampliación de su perímetro urbano hasta alcanzar 27 ha, con la construcción de una nueva muralla, así como en la configuración monumental de la zona del foro con la construcción del edificio augusteo - en terraza- y que aquí presentamos. Corresponde también a este periodo la construcción del edifico teatral $\mathrm{y}$, con bastante probabilidad, del acueducto que hoy apenas se conserva proveniente de la zona de El Almedral, a las afueras de la localidad de San Roque. Además de ello, en lo que concierne a su territorio, es también a partir de este momento cuando se documenta el establecimiento de una red de factorías de salazón y de alfares en el entorno de la bahía -vicus y villae- dependientes de la urbe carteinese, entre los que sobresale el vicus de Villa Victoria. ${ }^{6}$

\section{El edificio augusteo}

La construcción que hemos denominado como "edificio augusteo" se encuentra ubicada en la ladera suroriental del cerro del cortijo del Rocadillo. Su planta se dispuso

6 Bernal et alit 2006 y 2009; BlánQuez et ALII 2008 y 2011. 
en sentido perpendicular al templo republicano, en el borde de la meseta superior del citado cerro (Fig. 2). Se trata de una potente estructura construida en dos alturas: aterrazada en su mitad sur y con un espacio porticado en función de las evidencias materiales llegadas hasta nosotros en la parte más al norte. Dicho edificio orientó su fachada principal hacia el templo republicano y quedó situado junto a una insula tardo republicana por su lado oeste. ${ }^{7}$

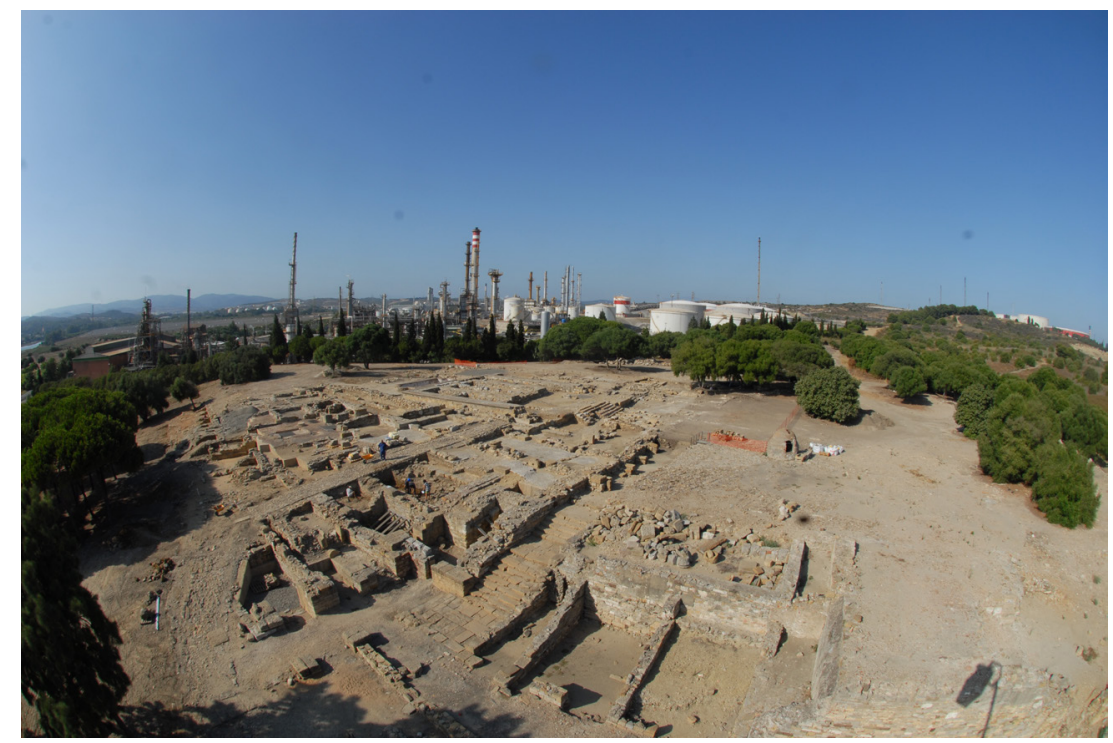

Fig. 2. Vista general del cerro del cortijo del Rocadillo, hoy derruido, con las construcciones romanas en superficie. (C) Proyecto Carteia UAM, 2009.

Conocemos el edificio a partir de las excavaciones llevadas a cabo en los años sesenta, en lo que entonces era la ladera sur del cortijo del Rocadillo aún en pie en aquella década. ${ }^{8}$ Gracias a uno de los dieciocho cortes excavados por sus investigadores se pudieron documentar diversos muros y elementos arquitectónicos pertenecientes a una construcción que denominaron como "edificio de los toros". Años más tarde el profesor F. Presedo, de la Universidad de Sevilla, continuó las excavaciones, ya en extensión, en toda esta área hasta casi completar su planta. ${ }^{9}$ No obstante, no llevó a cabo su publicación completa, ni su interpretación, cronología o posibles fases constructivas. De igual manera, tampoco asoció los elementos arquitectónicos allí hallados al mismo, sino que los adscribió al cercano edificio templario. Bien es verdad que la complejidad del edificio, construido en dos alturas, así como la superposición de sucesivas construcciones en época tardoantigua hacían difícil la adecuada interpretación del mismo. Paralelamente, las excavaciones del profesor Presedo

7 Romero 2011 y 2013.

8 Woods ET ALII 1967.

9 Presedo et alit 1982, 38-49. 
se interrumpieron en 1985, por lo que el edificio quedó sin terminar de excavarse ni completarse su estudio.

Con motivo del desarrollo del Proyecto Carteia de la UAM, en su segunda fase (2006-2013) retomamos la investigación del edificio, tanto en sus aspectos arquitectónicos -arqueoarquitectura- como estructurales y, junto con ello, se pudo contar también con nueva documentación a través de puntuales excavaciones dentro del mismo edificio a fin de obtener una secuencia estratigráfica apoyada, fundamentalmente, en materiales cerámicos. Contamos también, además, con interesante documentación inédita relacionada con las excavaciones llevadas a cabo por Presedo en este sector gracias a la cesión de su Legado Documental, por parte de su familia, a la UAM. $^{10}$

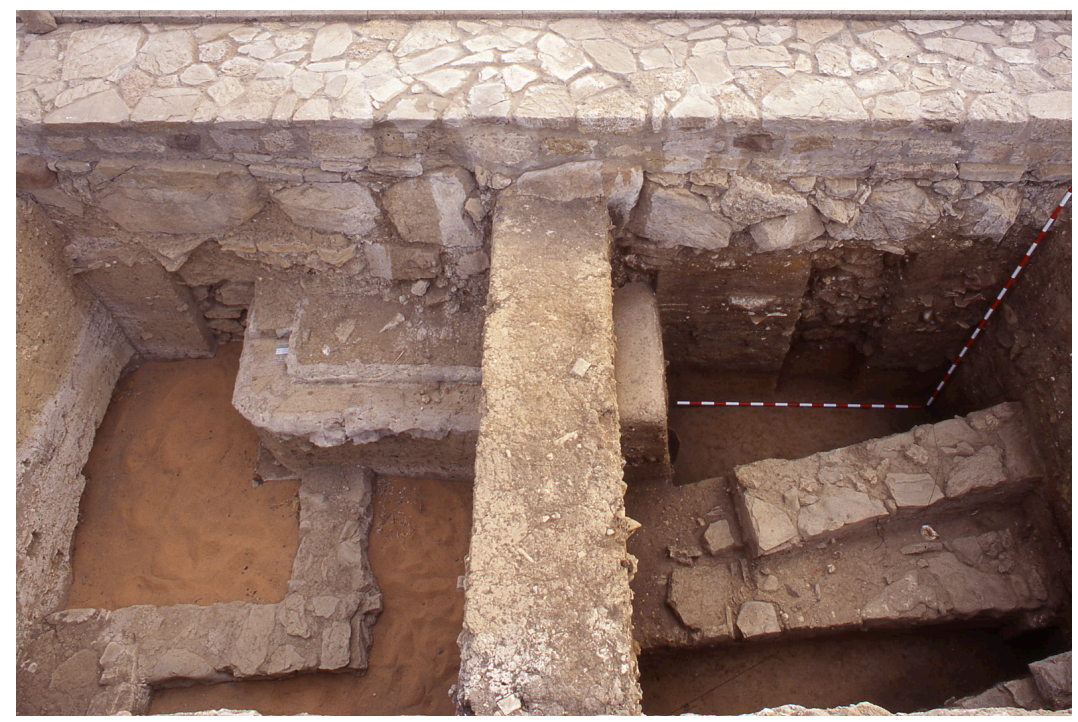

Fig. 3. Vista general de los altares púnicos cortados por la cimentación del podium del templo republicano de Carteia. (C) Proyecto Carteia UAM, 1998.

El edificio en cuestión se construyó, como decíamos, aprovechando en parte la meseta superior en la que se asentaba el cortijo del Rocadillo y, también en parte, aterrazado. Para su construcción se tuvo que llevar a cabo una potente infraestructura destinada a soportar la terraza superior, en toda su mitad sur, mientras que la parte más al norte apoyada sobre el propio suelo geológico de la meseta y sobre estructuras de aterrazamiento y constructivas más antiguas, tanto republicanas como púnicas. Éstas quedaron documentadas en la campaña de excavación que llevamos a cabo en el año 2009 (área 13 A y B) y su adscripción cultural de acuerdo con parámetros constructivos y materiales (cerámicos) bien documentados ya en otras áreas excavadas durante el primer sexenio del Proyecto Carteia entre 1994 y $1999^{11}$ (Fig. 3). De

10 BLÁNQUEZ - RoldÁn 2015.

11 BLÁNQUez 2006a, 301-316. 
igual manera y previo a la construcción de este edificio augusteo, la ladera sur del cerro estuvo parcialmente ocupada por probables construcciones republicanas y, bajo éstas, por otras más antiguas documentados en excavaciones dirigidas por Daniel E. Woods. ${ }^{12}$

Creemos interesante apuntar ya cómo los muros republicanos aparecidos en la ladera, junto a la escalera monumental (augustea) de acceso a la meseta superior, reutilizaron numerosos sillares púnicos que, en ocasiones, todavía mantenían evidencias de su original almohadillado que había sido retallado en el momento de dicha reutilización. Aunque algunos de estos muros traban entre sí, por el momento -dado el reducido espacio de excavación- no es posible determinar los espacios que configurarían. Ahora bien, en el caso concreto del muro que delimita el citado acceso escalonado (lado oeste) y que presenta, además, una posterior superposición de sillares augusteos, apunta a una fosilización de un acceso a la parte superior del cerro ya desde época púnica. También interesante es apuntar la existencia de una cisterna situada en la parte superior de la terraza, cortada cuando la construcción del edificio augusteo. Su cronología, con seguridad, no se puede concretar, dado que su excavación no es posible por estar toda esta parte sellada por el pavimento de opus signinum del propio edificio augusteo. Ahora bien, el forrado interior mediante un hormigón hidráulico de gran calidad apunta a una adscripción en época bárquida.

\subsection{La relación del edificio augusteo con la insula republicana}

La construcción del edificio augusteo afectó de manera importante a un edificio adyacente, previo al mismo, situado un poco más al oeste. Se trata de una domus que formaba parte de un conjunto construido en paralelo al templo, por su lado sur, datado en época tardorrepublicana gracias a las excavaciones realizadas en el mismo, tanto en su fachada sur (campañas de 1996 y 97) como en la norte (campañas de 2007 y 2009). La anterioridad de la domus con respecto al edificio augusteo es segura dado que este último ocupó y se superpuso sobre todo el lateral oriental de aquella.

La ubicación del edificio augusteo, con bastante probabilidad, reutilizó un espacio ya ocupado anteriormente; si bien con una funcionalidad y materiales constructivos distintos. Así, la nueva construcción, de planta rectangular, quedó constreñida -longitudinalmente- por la escalera de acceso a la plataforma superior del cerro (lado este) y la citada domus (lado oeste) y, por lo que respecta a sus lados cortos, por la existencia del templo (lado norte) y la caída en ladera (lado sur) problema, este último, solucionado mediante la construcción en terraza. Así, pues, el espacio disponible debió de resultar excesivamente estrecho y, seguramente por esta razón, se decidió ocupar parte de la domus anexa. Ello determinó el que el muro oriental de esta última fuera desmontado, $\mathrm{y}$ achicadas sus estancias para superponer parte del pórtico oeste de la nueva construcción. Ello conllevó alterar la simetría espacial de la propia domus pero, a la vez, una "convivencia" de ambas construcciones evidentemente buscada. El desmonte de los muros transversales que configuraban las habitaciones

12 Woods ET ALII 1967. 
de la domus y su posterior inserción en el muro perimetral (oeste) del nuevo edificio monumental, todavía hoy, se pueden observar tras un detenido análisis de las estructuras murarias conservadas. El eje de orientación del edifico augusteo apenas cambió con respecto al anteriormente establecido en la construcción de la domus, tan sólo se desplazó unos grados hacia el oeste (Fig. 4).

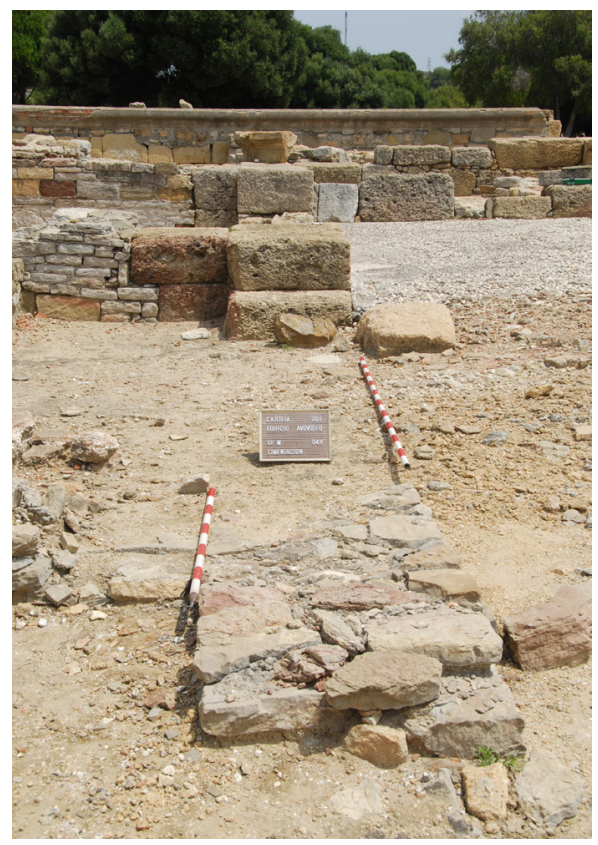

Fig. 4. Vista lateral del edificio monumental augusteo con los muros estructurales. (C) Proyecto Carteia UAM, 2011.

\subsection{Elementos estructurales}

El edificio augusteo se configuró mediante dos estructuras murarias formadas a su vez, cada una de ellas, por dos muros en ángulo recto, trabados entre sí, que formaban la base de sustentación de la terraza y, a la vez, estaban destinados a contener la presión de la parte superior de la ladera. La primera de dichas estructuras cierra en su lado este y sur la parte maciza de la terraza, mientras que la segunda -más externadefine hacia el sur estancias huecas (espacios D y E) y limita por el este con la ya citada escalera de comunicación entre la meseta superior y la parte baja de la ladera; o lo que es lo mismo, los dos niveles del edificio. Entre ambas estructuras murarias, se colocaron otros 2 muros perpendiculares a ellas que delimitan, a su vez, también espacios huecos (G y F) y que servían también como elementos de contención de la terraza hacia el norte y hacia el oeste (Fig. 5).

La original ubicación en ladera ha provocado que el extremo sur del edificio no se haya conservado, especialmente en su ángulo occidental; por el contrario, en el lado 
oriental se conservan al menos 3 pilares de apoyo de la terraza (UEM 8, 11 y 13) y un posible cuarto solo detectado en planta (UEM 7). Estos pilares traban con muros que compartimentaban el espacio bajo la terraza y definen, así, sucesivas estancias paralelas (B, C y D); a excepción del pilar UEM 13, que es exento.

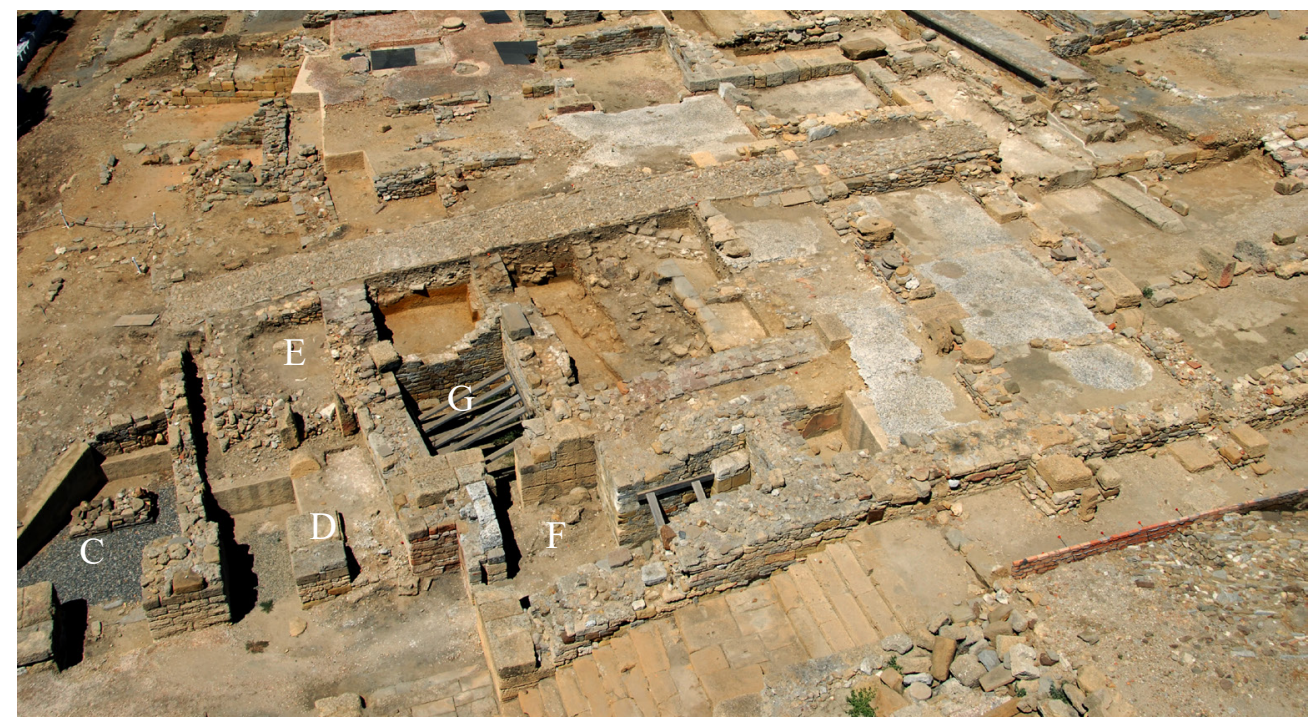

Fig. 5. Muro de la domus republicana cortado por la construcción del edificio monumental augusteo. (C) Proyecto Carteia UAM, 2011.

Por el lado este, estos pilares o apoyos puntuales de la terraza superior se alinean con el muro estructural de contención-sustentación de la misma y coinciden, ya en la terraza superior, con los puntos de apoyo de las columnas del pórtico. A su vez, éstos, ya por el lado este, tienen simétrica correspondencia con otros tantos, de modo que, en conjunto, configuran una galería cubierta de acceso en dirección N-S y que comunicaba con el inicio de la escalera.

El notable grado de destrucción de la parte sur del edificio ha permitido una excavación, casi quirúrgica, lo que ha facilitado un detallado estudio del sistema constructivo de esta parte del edificio, así como una secuencia estratigráfica, tanto de los elementos estructurales como de la cultura material mueble. Por el contrario, toda la parte norte del edificio, contenida por los citados muros estructurales, no se ha podido excavar por debajo del pavimento original del mismo ni, fuera ya del edifico, por debajo del pavimento de la plaza que también se ha conservado hasta nuestros días. Tan sólo fue posible intervenir en un pequeño sector-Área 13- en el que aparecieron los citados muros púnicos que fueron arrasados cuando la construcción del edificio augusteo para servir de cimentación del mismo. 


\subsection{La plataforma superior: pórticos y columnas}

La parte superior del edificio tiene planta basilical, de la que se conservan vestigios de pórticos en tres de sus lados, menos al sur que, apoyado en la muralla, no se ha conservado, dada la destrucción general del yacimiento en esta zona acentuada por su disposición en ladera; de hecho, de la plataforma de la planta superior sólo se conserva algo más de su mitad norte. Las columnas, propiamente dichas, del pórtico tampoco se conservan in situ, pero sí son visibles los dobles sillares (ostionera en su acepción más popular) de apoyo de las mismas y que configuran rectángulos de 1,20 x $0,90 \mathrm{~m}$. Son seis los apoyos originales conservados: los cuatro del pórtico norte, uno del oeste y uno más, ya del lado este. Dichos sillares se apoyaron, directamente, sobre muros estructurales de los que sólo uno es hoy visible. Corresponde al pórtico oriental y estaba construido en opus vittatum.

Otro elemento a destacar es la aparición in situ de una basa de esquina (también en ostionera). Era la correspondiente al punto de conjunción de los pórticos norte y oeste y apoyaba, directamente, sin argamasa, sobre los dobles sillares de apoyo. Se conservaba así gracias a su reutilización - empotrada- dentro de un muro tardío. Tipológicamente, era similar a dos más, también reaprovechadas, en otro muro asociado a una importante reutilización-remodelación del edificio augusteo, llevada a cabo en el interior del mismo, ya en época tardoantigua. Otras similares se encontraban también en superficie, ya sin contexto, repartidas por el entorno inmediato y fueron ya recogidas en excavaciones antiguas. ${ }^{13}$ Todas ellas pueden catalogarse como basas áticas formadas por dos toros y una escocia, recubiertas por una capa de estuco blanquecino - de apariencia marmórea- que daría a las columnas un aspecto ennoblecido. Todo ello, junto con otros elementos arquitectónicos hallados en la meseta del cerro del Rocadillo nos han permitido reconstruir el orden completo. ${ }^{14}$

Los pórticos laterales tienen una anchura de $4 \mathrm{~m}$, mientras que el pórtico norte, correspondiente al muro de fachada y que mira al templo mide 4,20 m de ancho. Los tres pórticos conservados estuvieron pavimentados mediante un conglomerado de pequeñas piedras calizas, blancas y grises, unidas con abundante argamasa de cal muy consistente, a modo de un opus signinum de color blanquecino y que apoya sobre una cama de cantos bien colocados. Dicho pavimento cubría también el área central del edificio. La excavación realizada en 2009 en este sector (Área 13) permitió corroborar, con seguridad, la coetaneidad de este pavimento y de la cama sobre la que se apoya con respecto a los sillares de sustentación de las columnas y establecer, así, una fecha $p . q$. para su realización.

Este suelo de signinum enrasaba con la parte superior de los sillares de sustentación de las columnas, apoyando sobre los mismos, y se disponía también en los espacios existentes entre cada punto de apoyo. Aunque este dato podría inducir a interpretar dicha pavimentación como resultado de una posible remodelación del edificio, tras las excavaciones realizadas hemos podido corroborar su coetaneidad, así como la inexistencia de elementos de evacuación de aguas. Todo ello nos habla de un

13 Woods ET ALII 1967, 61-64, lamina XIX.

14 Bendala - Roldán 2005, 156 y ss.; RoldÁn ET ALII 2006, 398-416. 
edificio cubierto, incluso, en su nave central y con una importante ocupación tardía del mismo en la que fueron reutilizados numerosos elementos arquitectónicos, si bien manteniendo en uso el mismo pavimento.

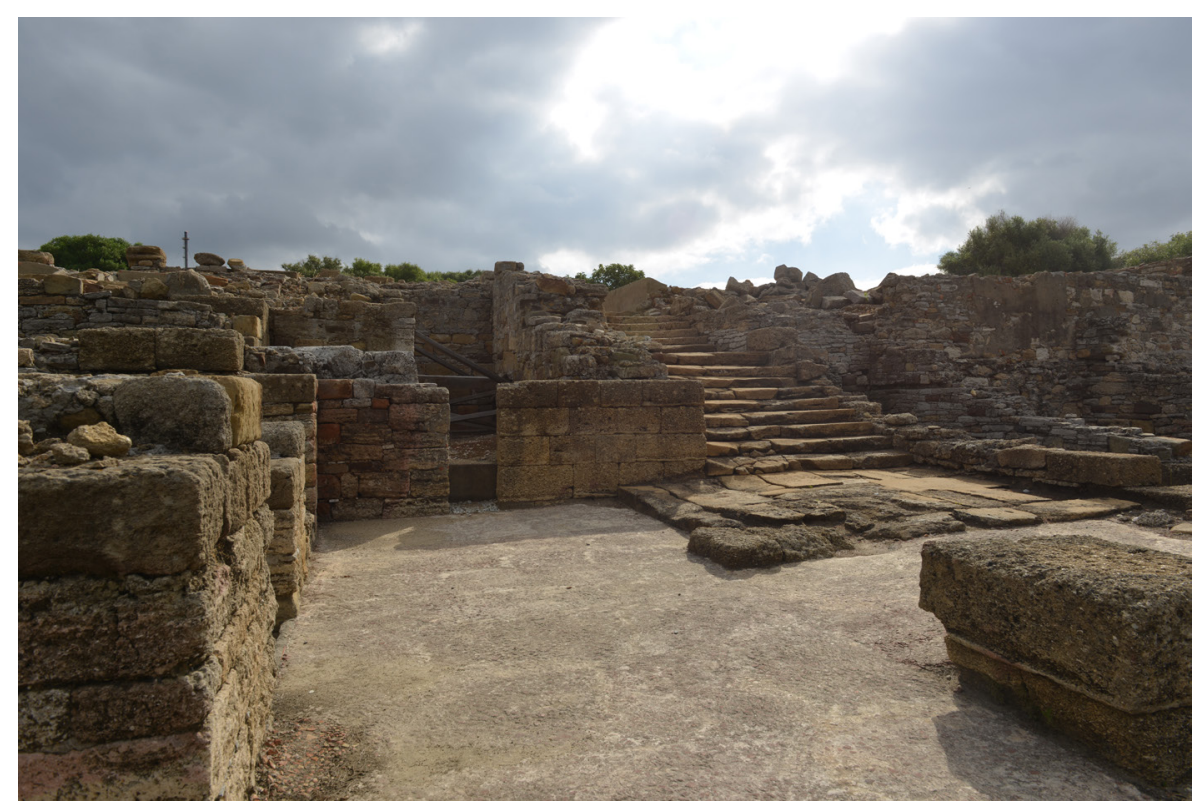

Fig. 6. Pasillo porticado pavimentado en opus signinum y escalinata, monumental, de acceso a la plataforma superior. (C) Proyecto Carteia UAM, 2013.

El pavimento original estuvo rematado por una lechada muy fina de argamasa que debió de proporcionar una superficie final lisa y uniforme, si bien por su uso y el paso del tiempo ésta ha desaparecido en su casi totalidad. Hay que recurrir a las zonas de esquina o de reciente excavación para poder apreciarlo; una realidad, pues, muy distinta a la que hoy se puede contemplar. También se pudo observar cómo el citado pavimento y su cama de piedras, de mediano tamaño, apoyaba sobre el muro estructural oriental que limita la plataforma; de hecho, se pudo comprobar cómo a éste se le había realizado un rebaje -a modo de zapata- para facilitar su apoyo. Todas estas características constructivas a la hora de materializar el pavimento del edificio monumental augusteo, junto con su disposición in situ y asociado a los sillares de apoyo a las columnas, hacen muy poco probable teorizar sobre la existencia de un pavimento más antiguo relacionado con el mismo.

En la parte baja -piso inferior de la estructura aterrazada- se conserva también otro pavimento original, recientemente restaurado, pero de diferente elaboración. (Fig. 6). Su disposición funcional era pavimentar la galería de acceso a las estancias del piso inferior, así como a la escalera de comunicación de ambas plataformas. Dicho pavimento se conserva hoy, sólo, en muy escasos puntos, pero suficientes como para determinar, por sus características formales, su posterioridad con respecto a las es- 
tructuras del edificio augusteo original, propiamente dicho. Ello es coincidente con la cronología flavia otorgada por Presedo en sus excavaciones. ${ }^{15}$ No obstante, dicha pavimentación no modificó la cota original del acceso ni los potenciales recorridos del edificio, en su conjunto.

\subsection{La escalera}

Una única escalera, situada en el lado oeste del edificio y paralela al mismo, permitía comunicar sus dos plantas y, a su vez, salvar el desnivel existente entre la meseta superior del cerro y la cota media del mismo o piso inferior del edificio. Se conserva hoy, en su práctica totalidad -14 peldaños- pero faltan, no obstante, los tres o cuatro últimos a juzgar por la altura de la plataforma superior bien definida por la cota de suelo de uso de la misma. La escalera se construyó a partir de grandes bloques de cantera, en piedra arenisca, dispuesta en tres tramos sucesivos separados por plataformas intermedias pavimentadas mediante losas del mismo material. Está precedida, en su parte inferior, por una plataforma o descansillo, pavimentado, en el mismo material y al que se accede desde la galería inferior del edificio que antes comentábamos pavimentado, a su vez, en opus signinum.

La escalera se construyó enmarcada, en su lado occidental, por el muro de contención este del edificio aterrazado, mientras que por el lado oriental delimita, a su vez, una serie de tabernae dispuestas, más hacia el este, en la parte baja del edificio. En ambos casos la escalera se adosa a los dos muros que la enmarcan, sin trabar con ellos, aunque su construcción pensamos que es coetánea al edificio augusteo. Sin embargo, tal y como apuntábamos anteriormente, el que el muro occidental se apoye en construcciones republicanas que, a su vez, reutilizaron sillares púnicos, junto con la configuración topográfica natural del cerro, nos permite hoy suponer -con bastante seguridad- la existencia de una escalera más antigua que tuvo que ubicarse en este mismo lugar.

\subsection{EI muro Norte de fachada}

El edificio que aquí presentamos tuvo su muro de fachada, con total seguridad, orientada al norte. Ello determina que se tuvo que acceder a su interior a partir de la plaza que se extiende al frente y, por el estudio de la planta del edificio, en sí mismo, también por el oeste, a la altura del pórtico de la domus adjunta.

Hacia el exterior la fachada norte se conserva, prácticamente, en toda su longitud alternando, en su construcción, sillares (de ostionera) con paños de opus vittatum (caliza margosa). Dicha alternancia está bien constatada en varios puntos de su fábrica de forma que los sillares, colocados a soga, se imbrican fácilmente con los alzados en opus vittatum. Este lienzo está muy cuidado, tanto en su construcción como en su forma y tamaño de los materiales constructivos. Estuvo originalmente revestido, en su cara exterior, por una capa de estuco y debió de tener algún tipo de decoración,

15 Presedo et aliI 1982. 
también estucada, ya que se han hallado numerosos fragmentos de la misma caídos, en el entorno inmediato, con detalles decorativos. También a esta fachada corresponden una serie de cornisas estucadas y policromadas aparecidas durante la excavación (Fig. 7).

Por lo que respecta a la cara interna del muro de fachada, coincidiendo con los alzados de opus vittatum, el muro se retranqueó para crear pequeñas hornacinas que fueron revestidas en el fondo y en sus laterales por opus signinum de buena calidad y de notable grosor $(14 \mathrm{~cm})$ forradas, a su vez, con placas marmóreas. No podemos afirmar, con seguridad, si dicho revestimiento formaba parte de la obra original pero, sea como fuere, sí, con seguridad, las citadas hornacinas.

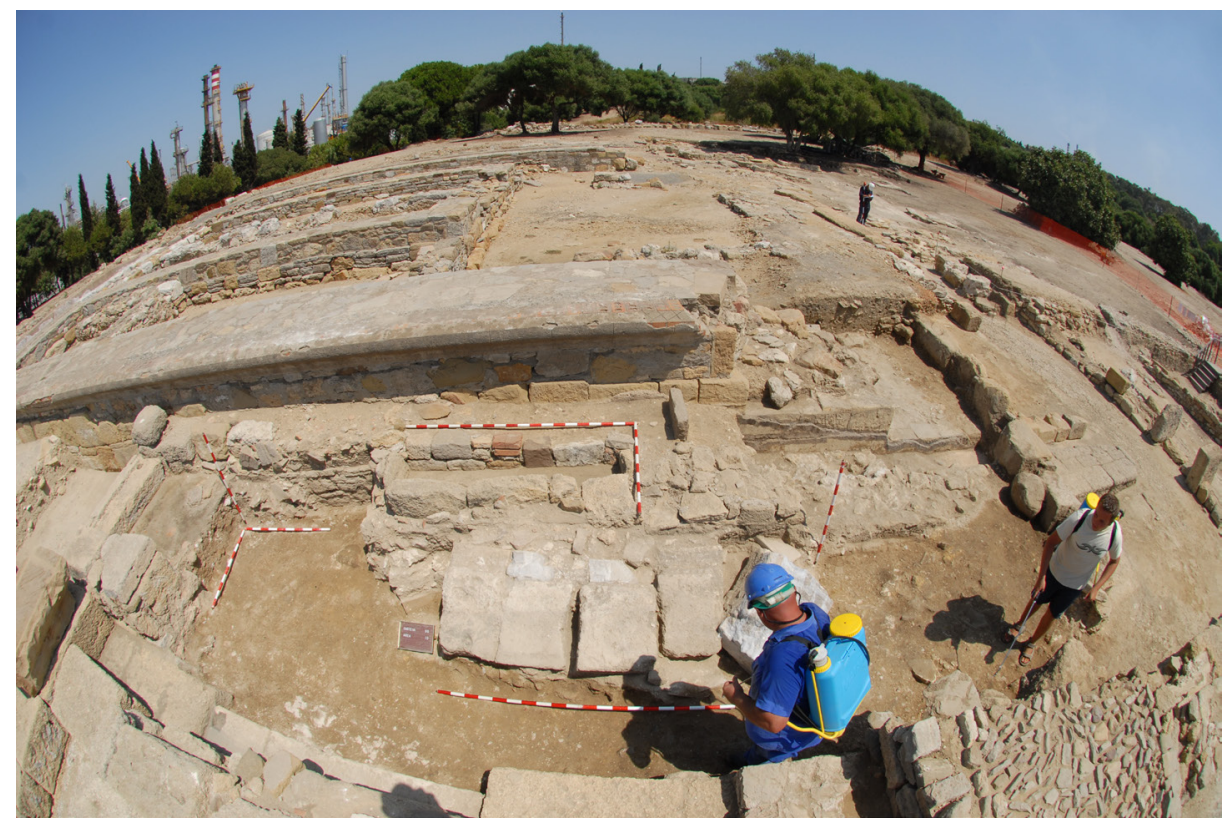

Fig. 7. Aparición in situ de las cornisas de la fachada de acceso al edificio monumental augusteo. (C) Proyecto Carteia UAM, 2009.

\subsection{Cronología}

La cronología de este edificio monumental que venimos analizando se apoya, tanto en la lectura estratigráfica de las diferentes estructuras arquitectónicas como en las excavaciones realizadas y su consecuente secuencia de los materiales cerámicos; junto a ello, además, contamos con el estudio formal de los elementos arquitectónicos que hemos readscrito al edificio.

Su fábrica amortizó estructuras de época republicana hasta el punto de, en ocasiones, apoyarse sobre ellas. Amortizó también, si bien de manera parcial, la domus republicana que continuó en uso y que hemos podido fecharla, gracias a su reciente 
excavación en la segunda mitad del s. I a.C. ${ }^{16}$ Todo ello nos aporta una primera fecha post quem, para la construcción de este edificio augusteo, a finales del periodo republicano.

Desde el punto de vista arqueológico, la excavación en la campaña de 2009 del área 13 permitió documentar estructuras anteriores a la construcción del conjunto augusteo. Dichas estructuras más antiguas pueden ser adscritas al primer asentamiento púnico. A su vez, éstas aparecieron amortizadas por nuevas construcciones murarias que, de nuevo, por sus técnicas constructivas y por los materiales cerámicos asociados a las mismas también correspondían al periodo púnico de la urbe antigua si bien al posterior momento bárquida (Púnico II), fechado a finales del s. II a.C. La amortización de estos últimos materializó un potente estrato que fechamos no más allá del primer cuarto s. I a.C. A su vez, el estrato que sirve de preparación al pavimento augusteo y que define un término post quem para la construcción del mismo, está formado por materiales de cronología muy diversa, entre el s. III y el s. II a.C.

Con respecto al estudio de los elementos arquitectónicos que hemos podido asociar al edificio del pórtico, su orden estaría configurado por basas de tipo ático, con 2 toros desiguales y una escocia entre dos listeles que presentan el imoscapo labrado en un único bloque. Los capiteles que, pensamos, hay que relacionar con este edificio son de tipo corintizante y se fechan, de manera general, entre la época tardo republicana y la augustea. ${ }^{17}$ Están labrados en dos piezas, con sus elementos vegetales bien tallados en piedra fosilífera y con marcado relieve. ${ }^{18}$ Tradcionalmente se asocia a las columnas un complejo entablamento configurado por un arquitrabe despiezado y friso con una característica decoración de prótomos de toro. Por último, las cornisas, con ménsulas decoradas alternando hojas de acanto y, de nuevo, prótomos de toro y con casetones abiertos con rosetas de cuatro pétalos, presentan también rasgos arcaizantes con reminiscencias del s. I a.C. Si bien dichos elementos han sido fechados tradicionalmente en época republicana, ${ }^{19}$ la presencia de cornisas de casetones, así como algunas características de los capiteles remiten a modelos augusteos. ${ }^{20}$

Todas las piezas están talladas con mucho detalle en la propia piedra, aun a pesar de que sobre ellas se aplicó, sistemáticamente, un grueso estuco que les confería una apariencia marmórea y, por ello, al edificio en su conjunto, un aspecto más monumental y uniforme.

\section{Definición e interpretación del edificio}

El edificio presenta una clara planta rectangular, con una longitud mínima de 35,5 m (no se puede determinar con precisión, dada la desaparición actual de su extremo

16 Romero 2011.

17 GuTIÉRREZ 1992, 185, nº 794.

18 Roldán - Bendala 2006, 400.

19 WoODS ET ALII 1967, 63.

20 Pensabene 1972, 53 y ss; Zanker 1992, 302; Gros 2001, 482 y 492; Roldán et aLit 2006, 407. No podemos asegurar, sin embargo, a qué lugar del edificio se asociaría dicho entablamento, dada su gran altura.. 
sur) y 20,5 m de ancho total: 12 x 7 pies; es decir, algo menos del doble de longitud que de anchura. Su perímetro quedó definido mediante muros de $0,80 \mathrm{~m}$ de anchura, excepto en su lado oriental, adosado a la escalera de acceso a la meseta superior, que se construyó con mayor anchura: 1,20 m. Los muros se realizaron en opus vittatum incluyendo, en ocasiones, sillares de ostionera y, ya de manera puntual, mampuestos de arenisca reutilizados. Como comentábamos, el lado sur del edificio no se conserva, aunque podemos suponer con bastante probabilidad que llegaría hasta apoyar en la propia muralla de la urbe; ocupó, pues, todo el espacio literalmente posible en este sector.

Sabemos por las excavaciones del Proyecto Carteia en su primer sexenio ${ }^{21}$ cómo, en esta parte sur de la urbe, la antigua muralla púnica se mantuvo en uso aun a pesar de la construcción de una nueva augustea provocada por la ampliación de la ciudad. Por ello, es plausible suponer que cuando se construyó este edificio monumental la muralla estaba visible y, por ello, bien se adosó a la misma, bien la sustituyó funcionando, entonces, como fachada de este edificio y como muralla de manera simultánea. El desnivel natural existente entre la meseta superior -punto de inicio del edificio- y la zona de la muralla - punto final del mismo-salvado, urbanísticamente, mediante una escalera, por un lado obligó a una construcción en terraza de éste y, por otro, posibilitó la construcción de un piso inferior en su mitad sur.

En su mayor parte, la estructura se asentó sobre terreno aluvial constituido por un conglomerado compacto de arcillas naturales ${ }^{22}$ si bien, puntualmente, reutilizó muros más antiguos de época republicana o anteriores púnicos como cimentación. Las excavaciones arqueológicas que hemos llevado a cabo han permitido documentar la existencia de potentes muros de aterrazamiento de época púnica que formaron parte del relleno de la terraza cuando se realizó la construcción augustea.

El edificio tuvo dos plantas en su parte sur, con una altura para la inferior de 4,50 $\mathrm{m}$. Esta altura queda determinada por un suelo de signinum en la zona baja de galería porticada y por el pavimento de la planta superior que en los dos casos se han conservado, parcialmente, hasta la actualidad. Dicha altura, técnicamente calculada, implica de manera obligada presuponer, para la planta baja, una cubierta adintelada, probablemente en madera (pino piñonero o alcornoque) ${ }^{23}$ y no abovedada como inicialmente se suponía. ${ }^{24}$ Así se explicaría, entonces, la ausencia de dovelas, tanto en las excavaciones antiguas realizadas en este sector ${ }^{25}$ como en las actualmente acometida por nosotros en 2007 y 2009. ${ }^{26}$ Esta planta inferior -o sótano- en contraladera, configuraba una serie de estancias paralelas, posiblemente espacios de almacenaje abiertos a un pasillo porticado de comunicación hacia la escalera monumental de subida a la meseta superior.

21 BLÁNQUez 2006b, 533 y ss.

22 FAZ 2013, 165.

23 FAZ 2013, 148-149.

24 RoldÁN ET ALII 2013, 176, fig. 114.

25 Woods 1967, 61-63.

26 RoLdÁN ET ALII 2007 y 2009. 
A su vez, la parte superior del edificio apoyada sobre la planta sótano en su mitad sur, estuvo delimitada en sus cuatro lados por muros, de los cuales se conservan sólo completo el norte y, ya parcialmente, los del este y el oeste; por el contrario, como ya hemos comentado, del lado sur nada se ha conservado. Aunque debido a la carencia de datos arqueológicos no podamos conjeturar el aspecto de las fachadas, más allá de la presencia de las puertas y el cornisamento ya mencionado en la fachada norte, sí podemos asegurar que no es posible considerar la existencia de pórticos abiertos en ninguna de ellas. Ello es debido al desnivel existente en el lado sur que apoyaría sobre la muralla y en el este por donde discurre la escalera. Con respecto al lado oeste, la presencia de la domus republicana colindante también lo impide y en el caso del lado norte, el muro de contorno con los accesos está bien documentado (Fig. 8).

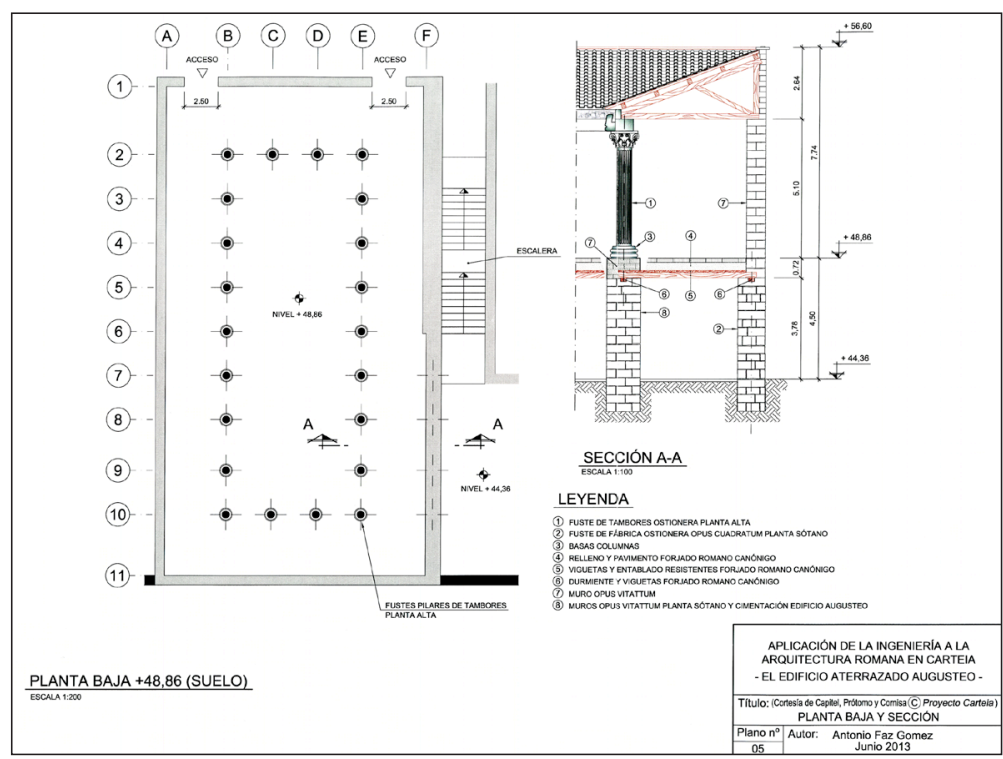

Fig. 8. Planta regularizada y sección del edificio monumental augusteo. (C) A. Faz Gómez, 2013.

Si nos basamos, de manera estricta, en los restos conservados nos encontramos ante un edificio de 33,5 x 18,20 m de dimensiones internas (sin contar los muros perimetrales), con media planta sótano, de cubierta adintelada en madera, más un piso superior al que se accedería por una escalera externa. Su planta porticada estuvo compuesta por un espacio central-spatium medium- de 9,4 $\mathrm{m}$ de ancho rodeado de un deambulatorio - porticus - de 4,40 m de ancho. El pórtico se configuró mediante nueve columnas -en su proyección longitudinal- y cuatro en la transversal; con una distancia entre ejes de 3,25 m (sentido longitudinal) y 3,30 m (sentido transversal). Ello materializó intercolumnios de $2 \mathrm{~m}$ de anchura con columnas entre 105 y $110 \mathrm{~cm}$ de diámetro en la basa y $80 \mathrm{~cm}$ del imoscapo. 
La altura de las columnas sería de 7,60 metros, ${ }^{27}$ mientras que si consideramos el entablamento mencionado tuvo que tener, de acuerdo con la reconstrucción que consideramos más canónica, $1,80 \mathrm{~m}$ de altura $;{ }^{28}$ todo ello proporcionaría una altura total de 9,40 m en el spatium medium. Una segunda posible reconstrucción del entablamento permite reducir su dimensión en $1,5 \mathrm{~m}$, si se apoyan los sillares engatillados, identificados como correspondientes al arquitrabe, en la parte trasera de los prótomos de toro que constituirían el friso, unificando ambas piezas. ${ }^{29} \mathrm{Si}$ bien esta reconstrucción resulta poco canónica, sin embargo, daría mayor esbeltez y proporcionalidad a los elementos arquitectónicos con respecto a las dimensiones del edificio. La ausencia de ninguna traza de posible escalera de comunicación con un hipotético piso superior sobre el pórtico -se trataría de un $3^{\circ}$ piso en el conjunto del edificio-, así como de elementos arquitectónicos que puedan corresponder a un doble orden de columnas, nos impide confirmar la propuesta de que la construcción hubiera tenido doble altura en el espacio central con terrazas o galerías sobre el pórtico.

Por lo que respecta a la posible interpretación de esta construcción monumental, en función de la documentación hasta la fecha obtenida, lo más probable es que pudiera tratarse de un edificio basilical, construido en época de Augusto con su fachada y doble acceso principal orientados al norte, hacia la plaza del templo; con una tercera puerta de acceso en la fachada oriental, enfilada al pórtico de la domus republicana. $\mathrm{Su}$ cronología augustea coincide con los primeros momentos de expansión de esta tipología basilical en Occidente, ya que no aparece en dicho ámbito antes de los primeros decenios imperiales, incluso en lugares de antigua romanidad como Glanum, Tarraco o Emporiae. En estos y otros ejemplos conservados, por lo general, la construcción de la basílica se acompañó con significativas remodelaciones en el foro y sus anexos administrativos, coincidiendo, generalmente, con la implantación del esquema de foro tripartito. ${ }^{30}$

Nuestro principal apoyo para considerar esta construcción como basílica es su propia ubicación en la parte alta del original cerro del Rocadillo, en la zona monumental de la urbe donde, en época republicana, se construyó el templo. Éste, a su vez, fue remodelado en época augustea con un nuevo acceso escalonado y la construcción de una fachada monumental hacia el norte que enmarcaba al templo propiamente dicho. Desde la misma se accedía, también mediante una escalinata, a un nuevo edificio adosado al citado templo que, en su día, ya interpretamos como un posible macellum. No existe confirmación arqueológica de la existencia del foro en este lugar en el momento de la construcción del templo (finales del s. II a.C.), pero sí podemos asegurar la configuración de un espacio foral con una amplia plaza delante del mismo a partir de época augustea. ${ }^{31}$ Todo ello, creemos, refuerza la propuesta interpretativa del edificio monumental como una basílica ya que, si bien ya se había mencionado como

\footnotetext{
278 veces el diámetro del imoscapo más la altura de la basa: 0,35 y del capitel: 0,80 .

28 RoldÁn EL ALII, 2003, 235 y fig. 134; Roldán EL ALII, 2006, 407.

29 FAz 2013, plano 5.

30 Gros 1996, 248.

31 RoldÁN ET ALII, 2013.
} 
tal, con anterioridad, ${ }^{32}$ creemos que es ahora a raíz de un análisis en profundidad de su ubicación con respecto a su entorno, de la interpretación de su planta como un edificio cubierto y de sus elementos estructurales y sus dimensiones cuando podemos definirla como tal con argumentos arqueológicos fundamentados.

Paralelamente, observamos cómo la propia planta del edificio -bien documentada durante su actual excavación- cumple, en cuanto a sus dimensiones $(35,5 \times 20,5 \mathrm{~m})$ la norma vitrubiana que establece cómo la anchura no debe ser inferior a un tercio de la longitud (De Arch V 1.4), si bien supera la mitad de la misma. De dimensiones cercanas al caso de Carteia son las republicanas de Cosa, con 35,89 x 27,05; ${ }^{33}$ Paestum, con $29,60 \times 17,60 \mathrm{~m}) ;{ }^{34}$ Tusculum $(30 \times 20 \mathrm{~m}){ }^{35}$ y la de Baelo $(35,83 \mathrm{x} 19,95)$, esta ya de época imperial. ${ }^{36}$

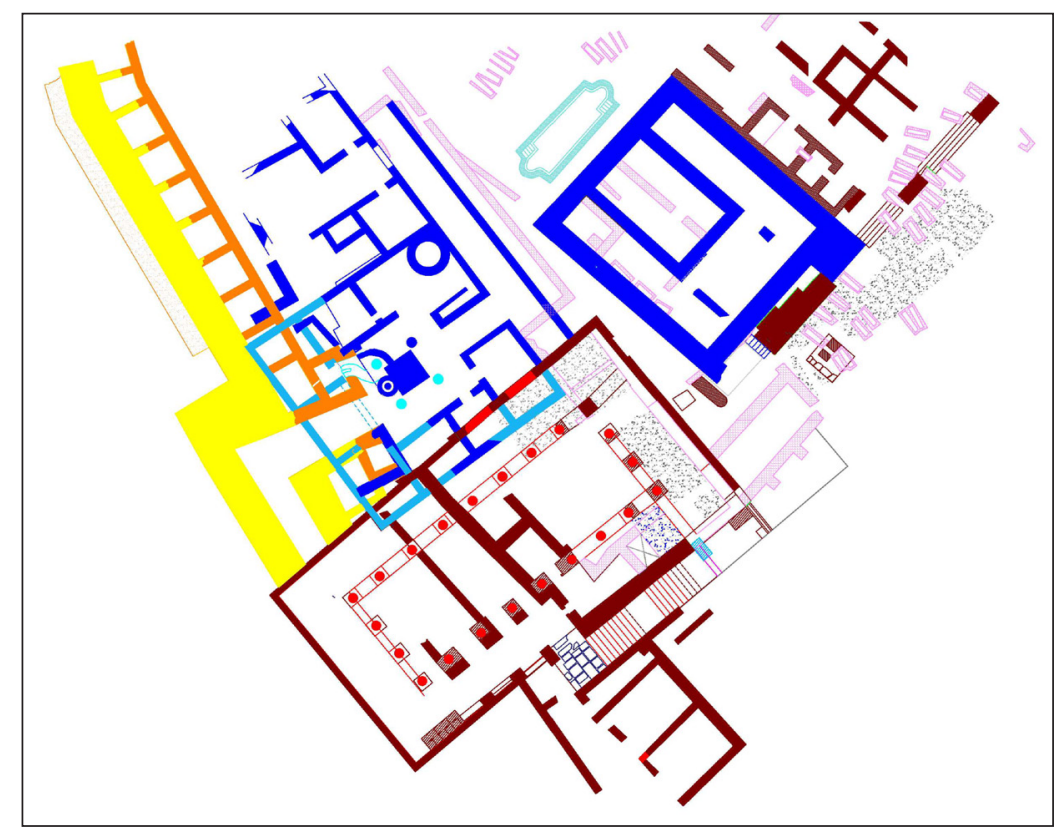

Fig. 9. Planta sintética de la domus republicana cortada, en su lado este, por la construcción del edificio monumental augusteo. (C) Proyecto Carteia UAM, 2015.

Presenta en su interior un deambulatorio porticus que determina un spatium medium cuya anchura es algo menor que el triple de la de los pórticos. (Fig. 9) El pórtico norte, al interior de la fachada del edificio, dispuso una serie de hornacinas -en parte conservadas- que quizás pudieran ser paralelizadas con las documentadas en la ba-

32 FAZ 2013.

33 BROWN - RICHARDSON 1993.

34 TORElli 1992.

35 Dupré 2005.

36 Le Ny - Paillet 2006. 
sílica de Baelo. En esta última los nichos son poco profundos, entre 8 y $11 \mathrm{~cm}$, con una anchura media de $2,07 \mathrm{~m}, \mathrm{y}$ a una altura con respecto al suelo original entre 1,25 y $1,45 \mathrm{~m}$. Según estudios realizados en el edificio de Bolonia, estos nichos servirían para encuadrar inscripciones honoríficas o dedicatorias, si no para paneles temporales de madera, para información administrativa o jurídica. ${ }^{37}$ También han sido reconocidos en la basílica de Assise aunque en este caso -como en el resto de los hasta ahora conocidos- son exteriores.

Por lo que respecta a su cubierta, lo más habitual a comienzos de época imperial -caso de Glanum y, ya en la península ibérica, en Tarraco, Clunia y Baelo- es que el espacio central tuviera doble altura y su segundo piso ventanas de iluminación, mientras que las naves laterales se remataban con terrazas o con tejado inclinado. ${ }^{38}$ En el caso de Glanum, la basílica construida a comienzos del s. I d.C., y correspondiente al segundo foro de la ciudad, ${ }^{39}$ habría tenido esta estructura con terrazas laterales y la cubierta del espacio central apoyada sobre muros. ${ }^{40} \mathrm{~A}$ su vez, la basílica de Baelo, de proporciones muy semejantes al edificio carteiense, se reconstruye, asimismo, con doble altura central, con un segundo orden de columnas en el piso superior y terrazas sobre el deambulatorio. ${ }^{41}$ Sin embargo, en el caso de Carteia no creemos oportuno defender una hipotética existencia de galerías o terrazas, ni de un segundo piso, como hemos expuesto antes con detalle, por falta de datos argumentales de carácter arqueológico. Somos conscientes, no obstante, de que esta propuesta es la más habitualmente constatada para este tipo de edificios.

Otros paralelos cercanos que, pensamos, merecen ser comentados al respecto son las basílicas de Saguntum y Ruscino, de cronología augustea y con dimensiones semejantes al edificio de Carteia: 40 × $20 \mathrm{~m}$ para la primera y $48,10 \times 19,20 \mathrm{~m}$ para la segunda. En Saguntum la basílica, situada en el flanco occidental del foro en paralelo al mismo, fue construida también en pendiente con un desnivel de hasta $12 \mathrm{~m}$ que favoreció - de igual manera- la construcción de un sótano para almacenaje, con estancias comunicadas entre sí. Su nave central habría tenido una anchura de $10 \mathrm{~m}$ y los deambulatorios de $5 \mathrm{~m}$, con un desarrollo longitudinal (calculado) de 10 columnas de las que se han hallado 4 basas con doble toro y sin plinto; estos elementos permiten calcular una altura para la nave central de $7 \mathrm{~m}$. No hay, como tampoco en Carteia, restos de un segundo orden de columnas, por lo que supone una restitución volumétrica con cubierta única sobre la nave central y las laterales. ${ }^{42}$

En el caso de Ruscino, cuyo foro ocupó una posición descentrada con respecto a los límites de la ciudad antigua, la basílica se situó de forma semejante al caso anterior, en sentido longitudinal paralelo al foro, en su lado occidental; ha sido fechada, tanto por datos arqueológicos como tipológicos, en época de Augusto. Por lo que respecta a su restitución se ha propuesto la nave central sobreelevada -con aberturas

37 Le Ny - PAillet 2006, 107.

38 Gros 1996.

39 Gros 1996, 249.

40 Gros - VARENNE 1984, 46, fig. 13.

41 Le Ny - Paillet 2006, 97 y ss.

42 Aranegui et alit 1987, 90-92; Aranegue 1990, 245-247. 
en la parte alta para iluminar el interior- a partir de muros que apoyan en las columnas interiores por intermedio de arquitrabes. Los pasillos laterales, que flanquean la nave central, estarían cubiertos con tejados opuestos a un agua. ${ }^{43}$ No presenta en la restitución un segundo orden de columnas en su piso superior. ${ }^{44}$ Una reconstrucción semejante sería, asimismo, posible en el caso del edificio carteiense.

La construcción de este edificio basilical en Carteia se produjo dentro de toda una importante remodelación de este sector de la urbe, en torno al foro, durante época augustea. Creemos significativo este aspecto dado que se sabe cómo fue durante aquel periodo cuando las basílicas adquirieron verdadera importancia en la composición de los foros. ${ }^{45}$ La basílica pasó, entonces, de ser un elemento complementario dependiente del foro - un locum comune- a configurarse tipológicamente como un edificio con entidad propia -un opus publicum - rodeada de muros y encerrada en sí misma. ${ }^{46}$ Vitrubio (V 1.4) utilizó la expresión loca adiuncta para designar su emplazamiento inicial lo que, según Gros, muestra bien el estatus secundario de estos edificios y su escasa autonomía monumental, ${ }^{47}$ a diferencia de las basílicas posteriores.

Fue también en época augustea cuando algunas basílicas forenses se dotaron de salas axiales identificadas con el aedes Augusti, valgan como ejemplos los casos de Fano, Sepino, Ruscino, Lucus Feroniae, Ordona, Iuvanum y Roselle ${ }^{48}$ y tiene lugar la introducción en las mismas del culto imperial. En este sentido, se ha señalado cómo el tribunal se subordinaba y se sometía, a la vez espacial y simbólicamente, al aedes Augusti, expresión de la autoridad imperial. ${ }^{49}$

En Carteia, la ausencia de restos de un posible aedes augusti, característico de esta tipología basilical, ${ }^{50}$ podríamos explicarlo si tenemos en cuenta la desaparición de, prácticamente, la mitad sur del edificio. Sea como fuere, no se trata de un elemento imprescindible, ya que la introducción del culto imperial en la basílica no siempre precisaría de la existencia de un aedes. Ejemplo de ello sería la basílica de Pompeya; o la más cercana de Baelo Claudia, donde quedaría relacionado, tan sólo, con la estatua de culto. ${ }^{51}$

Por último y en relación con la cronología augustea de nuestro edificio basilical, si consideramos la antigüedad de la ciudad -fundada como colonia latina en el 171 a.C.- podría haber existido una basílica más antigua; dada la consideración de este tipo de edificio como uno de los más representativos del modo de vida romano. ${ }^{52}$ No obstante, hasta la fecha y aun con más de 50 años de excavaciones, no ha sido posible identificarla. ${ }^{53}$ Por otro lado, habría que resaltar también cómo en Hispania la docu-

43 Barroul - Marichal 1987, 51.

44 Barroul - Marichal 1987, fig. 8 y 9.

45 Mar - Ruiz de Arbulo 1988, 278.

46 Gros 1984, 62; EtXebarria 2008, 194, nota 329.

47 Gros 1996, 240.

48 David 1983, 228-235; Mar - Ruiz de Arbulo 1987, 281.

49 DAVID 1983, 240.

50 DAVID 1983, 228-235.

51 Mar - Ruiz de Arbulo 1986, 282.

52 Gros 1996, 235.

53 No podemos descartar, sin embargo, la posibilidad de que dicho edificio más antiguo hubiera sido amortizado por la construcción de la nueva basílica augustea. 
mentación arqueológica de basílicas republicanas es, hasta la fecha, prácticamente inexistente, si exceptuamos la referencia a la basílica de Corduba en el 47 a.C. (Bell. Alex. 52). ${ }^{54}$ Igual ocurre con los foros republicanos, en su mayoría remodelados o rehechos en época imperial. ${ }^{55}$

Aun con todo, todavía la arqueología tiene mucho que decir en el caso de Carteia. Como mera hipótesis pendiente de confirmación -arqueológica- llamamos la atención sobre la parcial amortización del edificio de atrium en el momento de construcción de este edificio de carácter monumental augusteo. Aquel edificio, evidentemente más antiguo, bien pudo haber asumido funciones de orden jurídico, administrativo y comercial a partir de su construcción en época tardorepublicana; de hecho más de la mitad de la manzana (parte occidental) sigue pendiente de su completa excavación. En esta hipótesis, pues, aquellas posibles funciones allí desarrolladas habrían sido sustituidas por la construcción del edificio basilical y podríamos considerar, así, al citado edificio de atrio antecedente funcional de la basílica. ${ }^{56}$ Sea como fuere, el que la construcción de esta posible basílica respetara el atrio e, incluso, dispusiera una puerta lateral de comunicación con el pórtico de su fachada apunta a un deseo de relación más que meramente espacial.

Pero la remodelación augustea de la urbe de Carteia conllevó otras iniciativas urbanísticas además de las modificaciones comentadas llevadas a cabo en el área monumental del cortijo del Rocadillo (remodelación del anterior templo republicano; un posible macellum, adosado al mismo; o la construcción del posible edificio basilical). Las excavaciones realizadas al noroeste de la urbe, en la zona de la muralla, ponen de manifiesto una importante ampliación de su perímetro amurallado hasta ocupar, prácticamente, 27 ha, frente a las menos de 4 de la urbe púnica. A ello habría que añadir, también, la construcción del teatro, ${ }^{57}$ situado en la parte alta de la urbe y, quizás, la construcción de uno de sus acueductos, el que llegaba por el lado noreste y que se reconoce en la zona de El Almendral.

Si bien es cierto que para el caso del acueducto, a día de hoy, no contamos con documentación suficiente como para establecer su cronología de manera argumentada, no ocurre lo mismo con el teatro. En éste último, ya desde el inicio del proyecto que llevamos a cabo desde la UAM, trabajamos en él. ${ }^{58}$ Primero mediante la reexcavación de antiguos cortes acometidos por F. Presedo, que habían quedado inéditos; ${ }^{59}$ posteriormente, mediante el estudio de su Legado Documental ${ }^{60}$ y, desde 2013 hasta la actualidad, a través del análisis de su estructura arquitectónica y de sus características constructivas en el marco del Proyecto I+D+i (HAR2012-36963-C05-01), con

54 Mar - Ruiz de Arbulo 1986, 282.

55 Gros 1996, 248; JimÉNEZ 2009, 42.

56 Respecto a la relación entre ambos tipos de edificios véase Gros 1996, 238, 239; EXTEBARRIA 2008, 193.

57 ROLDÁN 2015.

58 ROLDÁN ET ALII 1998, 174-178; 2003, 251-260.

59 ROLDÁN ET ALII 2006, 52.

60 BLÁNQUEZ - Roldán 2014 (e.p.). 
importantes resultados en relación con una mejor definición de su planta y diferenciación de sus fases constructivas. ${ }^{61}$

Con respecto a la muralla, si bien ya pudimos estudiarla durante las excavaciones del primer sexenio, ${ }^{62}$ ha sido durante las campañas de 2009 y 2011, en el ámbito de la Fase II del Proyecto Carteia, cuando su aparición en un nuevo sector de trabajo -al oeste de la urbe- ha permitido obtener una buena secuencia estratigráfica. (Fig. 10) Si bien el estudio del material cerámico está, todavía, en curso -formará parte de la preceptiva Memoria del segundo sexenio- su construcción en época augustea ha quedado bastante precisada; a la vez que la información urbanística proporcionada ha sido también más que notable. Así, ha quedado confirmado cómo, a partir del original recinto murario púnico en la parte suroccidental de la urbe, en época augustea, se construyó uno nuevo que, por su notable mayor perímetro dejó a aquella dentro del nuevo trazado; si bien, a lo largo de casi un centenar de metros, discurrió en paralelo a la muralla púnica. En concreto para aprovechar, así, el lugar en el que, con bastante probabilidad, estuvo la puerta oeste de la antigua urbe púnica. ${ }^{63}$ Todas estas cuestiones -creemos- ponen en evidencia la existencia de una importante renovación de la urbe carteiense a partir de la instauración del Principado y que pudo haberse mantenido, tras la muerte de Augusto, durante los primeros momentos de la época julioclaudia.

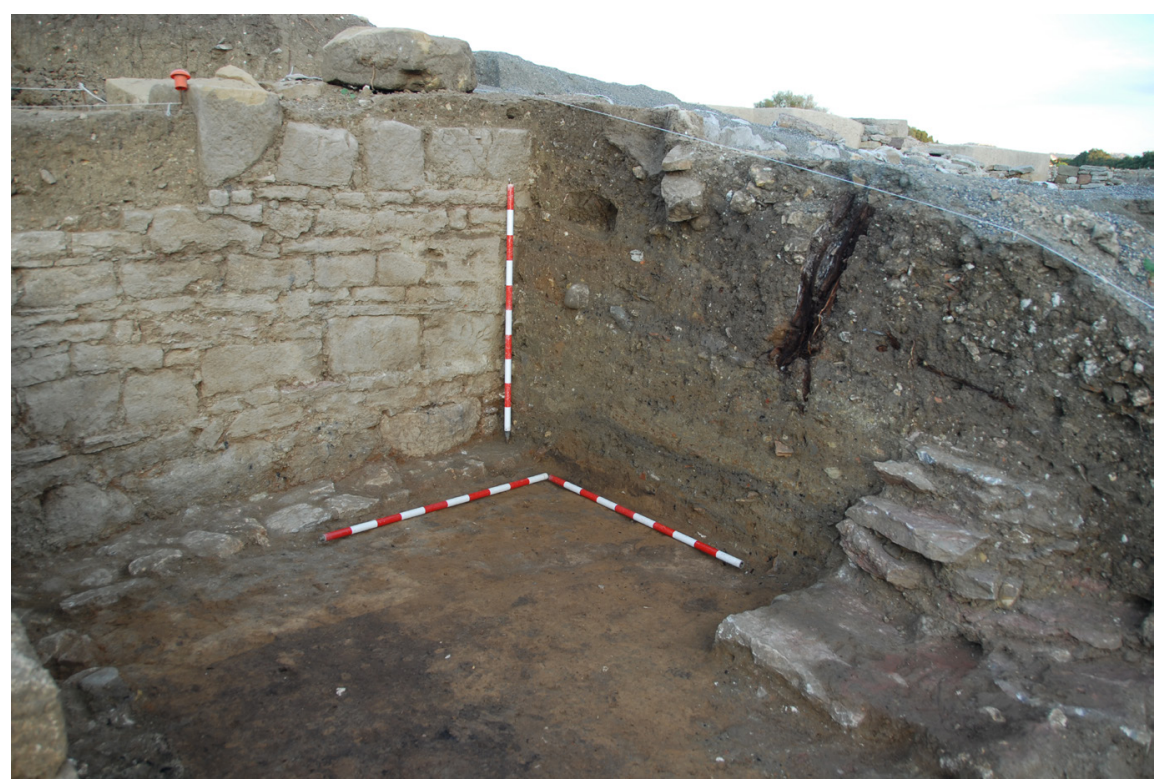

Fig. 10. Excavación de la casamata $n^{\circ} 3$ de la muralla bárquida (lado sur de la urbe). La hilada superior corresponde al umbral de entrada a la misma. (C) Proyecto Carteia UAM, 2007.

61 RoLDÁN 2015.

62 RoldÁn ET ALII 2006.

63 Para su análisis constructivo ver BLÁNQUEZ ET ALII 2015 (e.p.). 
Dicha renovación podríamos relacionarla, aunque no solo, con el final de las guerras civiles y las consecuencias que las mismas debieron acarrear a la urbe de Carteia tras el triunfo de Cesar sobre Pompeyo por su adscripción al bando pompeyano. ${ }^{64}$ Así pues, superadas las secuelas de la guerra civil y con la llegada de Augusto al poder se habría acometido en Carteia un nuevo plan urbanístico de notable envergadura. Coincidente con ello está también la cuestión relacionada con su estatus jurídico, tratado en sucesivas ocasiones por diferentes autores ${ }^{65}$ Nos referimos al posible cambio de su estatus como colonia a municipio avalado por escasos, pero interesantes, datos históricos y epigráficos. En especial destacaríamos la existencia de una inscripción con el nombre de munic que, procedente de Carteia, fue hallada en el "Rocadillo", si bien se desconocen las circunstancias del hallazgo. Es probable que, dado que formaba parte de la antigua colección del Ayuntamiento de San Roque, configurada en su mayor parte por piezas procedentes de las excavaciones de Martínez Santa-Olalla, provenga de sus excavaciones en este yacimiento entre 1953 y $1962 .{ }^{66}$ Dicho epígrafe, tradicionalmente, ha sido fechado en el s. I d.C. y, ya más recientemente, en la primera mitad del s. II por sus características paleográficas. ${ }^{67}$

Parece posible pensar, pues, que Carteia habría pasado a tener el estatus de municipum civium romanorum -como sucedió en las colonias latinas de Italia a consecuencia de la promulgación de la Lex Iulia de civitate en el 90 a.C., cuando abandonaron sus pretores por IIII viri- si bien no hay evidencias de ello para Carteia $^{68} \mathrm{y}$, por tanto, no podemos apuntar una cronología segura para el momento en que se produjo dicho cambio en esta ciudad. En este sentido se ha sugerido la segunda mitad del s. I a.C. y habría implicado, como en las colonias itálicas, una reorganización de su gobierno local coincidente, además, con un cambio de las emisiones monetales. ${ }^{69}$

Sabemos que fue, precisamente, en aquel periodo cuando comenzaron a aparecer en Carteia amonedaciones con la fórmula IIII viri, aunque de manera indistinta con diferentes cargos. Dichas emisiones han quedado muy bien fechadas a partir de los últimos hallazgos que hemos realizado, en 2009 y 2013, en la excavación de la muralla púnica al oeste de su urbe. Durante las mismas ha sido posible reconocer, en una de las casamatas bárquidas reutilizada en época republicana, lo que, parece, fue un taller de emisión monetal y, dentro del mismo, un conjunto de monedas en su mayoría pertenecientes a la ceca de Carteia. En concreto destacaríamos un cuadrante (CRT 13. UE 113084/5) con anverso con cabeza de Neptuno a derecha, detrás tridente y delante IIII VIR TER; por su parte, en el reverso aparece representado un delfín a derecha, encima CARTEIA y debajo C.MINI Q.F. que puede ser datado hacia el 45 a.C. ${ }^{70}$ Dadas las complicadas circunstancias por las que atravesó Carteia durante este periodo habría quedado pendiente dotar a la ciudad de una apariencia más acorde con

64 Caballos Rufino 1994, 152; Bendala - Roldán 2005, 154.

65 Wulf 1989; Pena 1988; FEAR 1994, entre otros.

66 Del Hoyo 2003, 360-361; RoldÁN ET ALII 2006, 11 con bibliografía anterior.

67 Del Hoyo 2003, 360-61.

68 FEAR 1994, 300.

69 SÁez - Blanco 1996, 261.

70 ArÉvalo ET ALII 2014. 
su nuevo estatus jurídico de municipium civium romanorum, cambio que habría sido, sino iniciado, sí ampliado años más tarde con el comienzo del Principado.

\section{BibLIOGRAFÍA}

Aranegui, C. (1990): “Sagunto", [en] C. Aranegui, Sagunto - W. Trillmich - P. Zanker (eds.), Stadtbild und Ideologie. Die Monumentalisierung hispanischer Städte zwischen Republik und Kaiserzeit. Madrid 1987, München, 241-250.

Aranegui, C. - Hernández, E. - López Piñol (1987): “El Foro de Saguntum: La planta arquitectónica", [en] Los foros romanos de las provincias occidentales, Madrid, 73-97.

ArÉvalo González, A. (2008): "La organización y producción de moneda en la Hispania Ulterior”, [en] M. Campo (coord.), Els tallers monetaris: organización i producción, Barcelona, 43-58.

Arévalo González, A. - Blánquez Pérez, J. - Roldán Gómez, L. (2014): “El taller monetal de Carteia (San Roque, Cádiz). Recientes testimonios arqueológicos", [en] XV Congreso Nacional de Numismática, Madrid (e.p.).

Barroul, G. - MARichal, R. (1987): "Le fórum de Ruscino", [en] Los foros romanos de las provincias occidentales, Madrid, 45-54.

Bendala Galán, M. - Roldán Gómez, L. (2005): "El templo romano republicano de Carteia (Hispania) y su problemática arqueológica e histórica", [en] X. Lafon - G. Sauron (eds.) Théorie et pratique de l'architecture romaine. Études offertes à Pierre Gros, Aix-enProvence, 153-166.

Bernal Casasola, D. - Blánquez Pérez, J. - Roldán Gómez, L. - Díaz Rodríguez, J. J. (2009): "Una cetaria anexa en el barrio alfarero de Carteia. Actividad arqueológica preventiva en la parcela R-3 de Villa victoria (San Roque, Cádiz)”, Caetaria 6-7, 459-466.

Bernal Casasola, D. - Díaz Rodríguez, J. J. - Blánquez Pérez, J. - Prados Martínez, F. - Roldén Gómez, L. (2006): "Villa Victoria, una figlina altoimperial en el territorium de Carteia", Almoraima 33, 235-250.

BLÁNQUEZ PÉREZ, J.

(2006a): "La nueva ciudad púnica de Carteia", [en] L. Roldán Gómez - M. Bendala Galán - J. Blánquez Pérez - S. Martínez Lillo (dirs.), Estudio Histórico-arqueológico de la ciudad de Carteia (San Roque, Cádiz), (= Arqueología Monografías 24), Madrid, 297-370.

(2006b): "Sector púnico", [en] L. Roldán Gómez - M. Bendala Galán - J. Blánquez Pérez - S. Martínez Lillo (dirs.), Estudio Histórico-arqueológico de la ciudad de Carteia (San Roque, Cádiz), (=Arqueología Monografías 24), Madrid, 531-540.

(2014): “Arqueología urbana. Espacios domésticos del mundo fenicio y púnico en el suroeste de la Península Ibérica", [en] B. Costa - J. H. Fernández (eds.), Arquitectura urbana y espacio doméstico en las sociedades fenicio-púnicas. XXVIII Jornadas de Arqueología fenicio-púnica (Eivissa, 2013) (= Treballs del Museu Arqueològic d'Eivissa i Formentera), Ibiza, 145-190.

Blánquez PÉRez, J. - RoldÁn Gómez, L. (2014): “Los Legados Documentales y la reinterpretación de las investigaciones arqueológicas del pasado siglo XX. El Centro Documental de Arqueología y Patrimonio de la Universidad Autónoma de Madrid (CeDAP de la UAM), [en] 150 años de arqueología: teoría y método de una disciplina, IV Congreso 
Internacional de Historia de Arqueología III Jornadas de Historiografía de la Arqueología SEHA-MAN [11, 12 y 13, diciembre 2014], (e.p.).

Blánquez Pérez, J. - Roldán Gómez, L. - Bernal Casasola, D. - Díaz Rodríguez, J. J. (2008): "La Necrópolis del barrio alfarero de Villa Victoria en Puente Mayorga, San Roque (Cádiz)", Almoraima 36, 105-118.

(2011): "The early imperial port structures at Villa Victoria. A jetty in de industrial district of outskirt of Carteia", [en] Meetings between cultures in the ancient Mediterranean. 17th International Congress of Classical Archaeology, Italian and foreign Archaeological Research Institutes, Bollettino di archeologia on line 2011. Direzione Generale per le Antichitá. Número 1, 2011/II, Roma.

Blánquez Pérez, J. - Roldán Gómez, L. - Jiménez Vialás. H. (2015): “La nueva muralla púnica de Carteia (San Roque, Cádiz). Investigaciones del Proyecto Carteia Fase II (20062013)", Lvcentvm (e.p.).

Brown, F. E. - Richardson, E. H. - Richardson, L. (1994): Cosa III. The Buildings of the Forum. Colony, Municipium, and Village, (=Memoirs of the American Academy in Rome XXXVII), Pennsylvania.

Chaves Tristán, F. (1979): Las monedas hispano-romanas de Carteia, Barcelona.

DAVID, J. M. (1983): "Le tribunal dans la basilique : évolution fonctionnelle et symbolique de la République à l'Empire”, [en] W. Grapius (ed.), Architecture et société, Paris, 219-245.

Dupré Raventós, X. (2005): “La basilica di Tusculum”, [en] X. Lafon - G. Sauron (eds.), Théorie et pratique de l'architecture romaine. Études offertes à Pierre Gros, Aix-en-Provence, 69-80.

EtXebarRia AKAITURRI, A. (2008): Los foros romanos republicanos en la Italia centro-meridional tirrena. Origen y evolución formal, Madrid.

FAz Gómez, A. (2013): Aplicación de la ingeniería a la arquitectura romana en Carteia: el edificio aterrazado augusteo Trabajo de Fin de Máster en Arqueología y Patrimonio, Universidad Autónoma de Madrid, (inédito).

FeAr, A. T. (1994): "Carteia, from Colonia Latina to Municipium C.R.", [en] Actas del II congreso de Historia de Andalucía, Córdoba, 295-301.

Gros, P.

(1984): “La basilique du Forum selon Vitruve: la norme et l'expérimentation", [en] Bauplanug und Bautheorie der Antike, Berlín, 49-69.

(1996): L'Architecture romaine 1. Les monuments publics, Paris.

(2001): L'Architecture Romaine 2. Maisons, palais, villas et tombeaux, Paris.

Gros, P. - VARÈne, P. (1984): "Le fórum et la basilique de Glanum: problèmes de chronologie et de restitution", Gallia 42, 21-52.

Gutiérrez Behemerid, M. A. (1992): Capiteles romanos de la Península Ibérica (= Studia Archaeologica 81), Valladolid.

JimÉnez SAlvador, J. L. (2009): "Los foros en las provincias de Hispania. Estado de la cuestión", [en] J. M. Noguera Celdrán (ed.), Fora Hispaniae. Paisaje urbano, arquitectura, programas decorativos y culto imperial en los foros de las ciudades hispanorromanas (= Monografías 3), Murcia, 37-64.

Le Ney, C. - Paillet, J. L. (2006): “La basilique de Baelo-Claudia: Étude architecturale”, [en] Actas I Jornadas internacionales de Baelo Claudia: balance y perspectiva (1966-2004), Sevilla, 93-136. 
Mar, R. - Ruiz de Arbulo, J. (1988): “Algunos ejemplos hispanos de la introducción del culto imperial en las basílicas forenses", [en] J. González - J. Arce (eds.), Estudios sobre la Tabula Siarensis (= Anejos de AEspA 9), Sevilla, 277-304.

Pena, M. J. (1988): "Nota sobre Livio, XLIII, 3. La fundación de la Colonia de Carteia", [en] Homenaje al Profesor Eduardo Ripoll Perelló, 26-276.

Pensabene, P. (1972): Scavi di Ostia VII, I capitelli, Roma.

Presedo Velo, F. - Muñiz Coello, J. - Santero Saturnino, J. M. - Chaves Tristán, F. (1982): Carteia I. ( =Excavaciones arqueológicas en España 121), Madrid.

RoldÁn GómEz, L. (2015): "El teatro augusteo de Carteia. Nueva documentación arqueológica", [en] 2on Congrés Internacional D’Arqueologia i Món Antic. August i les provínces occidentals. 2000 aniversari de la mort d'August, Tarragona, 95-101.

Roldán Gómez, L. - Bendala Galán, M. - Blánquez Pérez, J. - Martínez Lillo, S. (1998): Carteia, Madrid.

(2006): Estudio Histórico-arqueológico de la ciudad de Carteia (San Roque, Cádiz), (= Arqueología Monografías 24), Madrid.

Roldán Gómez, L. - Bendala Galán, M. - Blánquez Pérez, J. - Martínez Lillo, S. Bernal Casasola, D. (2003): Carteia II, Madrid.

Roldán Gómez, L. - Blánquez Pérez, J. - Bendala Galán, M. (2013): "Nuevas aportaciones al estudio del área monumental de Carteia", [en] R. Mª Cid López - E. García Fernández (eds.), Debita Verba II. Estudios en homenaje al profesor Julio Mangas Manjarrés, Oviedo, 121-138.

Roldán Gómez, L. - Blánquez Pérez, J. - Bernal Casasola, D. - Díaz Rodríguez, J. J. (2010): "Mudanças da paisagem cultural na baia de Algeciras (Cádis, Espanha)", [en] C. Corsi - F. Vermeulen (eds.), Changing Landscapes. The impact of roman towns in the Western Mediterranean (= Ricerche series maior 1), Évora, 217-236.

Roldán Gómez, L. - Blánquez Pérez, J. - Martínez Lillo, S. (2009): Proyecto Carteia. Fase II (2006-2011). Memoria definitiva. Campaña 2009, Original depositado en la Delegación de Cultura de la Junta de Andalucía en Cádiz.

Roldán Gómez, L. - Blánquez Pérez, J. - Martínez Lillo, S. (coords.), (2013): Guía del Museo Municipal de San Roque (Cádiz), Madrid.

Roldán Gómez, L. - Blánquez PéRez, J. - Marmtínez Lillo, S. - Bendala Galán, M. (2007): Proyecto Carteia. Fase II (2006-2011). Memoria definitiva. Campaña 2007, Original depositado en la Delegación de Cultura de la Junta de Andalucía en Cádiz.

Romero Molero, A.

(2011): "La domus republicana de Carteia. Una revisión de las excavaciones de F. Presedo", Almoraima 39, 105-114.

(2013): La domus republicana de Carteia (San Roque, Cádiz), Másters de la UAM, año académico 2010-2011, UAM ediciones CD, Madrid.

Sáez Bolaño, J. A. - Blanco Villero, J. M. (1996): Las monedas de la Betica romana. Vol I. Conventus Gaditanus, San Fernando.

Torelli, M. (1992): "Paestum romana", [en] Posidonia-Paestum, Atti del Ventisettesimo Convegno di Studi sulla Magna Grecia, Taranto 1987, Taranto, 33-115.

Woods, D. E. - Collantes de Terán, F. - Fernández-Chicarro. C. (1967): Carteia (= Excavaciones Arqueológicas en España 58), Madrid. 
WulfF Alonso, F. (1989): “La fundación de Carteya: Algunas notas”, Studia Historica: Historia Antigua 7, 43-58.

ZANker, P. (1992): Augusto y el poder de las imágenes, Madrid. 